\title{
FISH mapping of the sex-reversal region on human chromosome 9p in two $\mathrm{XY}$ females and in primates
}

\author{
Zhihong Shan ${ }^{1,2}$, Bernhard Zabel ${ }^{3}$, Udo Trautmann ${ }^{4}$, Ulrike Hillig ${ }^{5}$, Chris Ottolenghi $^{6}$, \\ Yayu Wang ${ }^{1,2}$ and Thomas Haaf ${ }^{1}$
}

\author{
${ }^{1}$ Max-Planck-Institut für Molekulare Genetik, Berlin, Germany; ${ }^{2}$ Yunnan Center for Medical Genetics, People's \\ Hospital of Yunnan Province, Kunming, China; ${ }^{3}$ Kinderklinik, Johannes Gutenberg-Universität Mainz; ${ }^{4}$ Institut für \\ Humangenetik, Friedrich Alexander Universität Erlangen-Nürnberg; ${ }^{5}$ Zentrum für Humangenetik, \\ Philipps-Universität Marburg, Germany; ${ }^{6}$ Institut Pasteur, Paris, France
}

\begin{abstract}
Accumulating evidence suggests that haploinsufficiency of a dosage-sensitive gene(s) in human chromosome 9p24.3 is responsible for the failure of testicular development and feminisation in XY patients with monosomy for $9 p$. We have used molecular cytogenetic methods to characterise the sex-reversing $9 p$ deletions in two XY females. Fluorescence in situ hybridisation (FISH) with YACs from the critical 9p region containing an evolutionarily conserved sex-determining gene, DMRT1, is a very fast and reliable assay for patient screening. Comparative YAC mapping on great ape and Old and New World monkey chromosomes demonstrated that the critical region was moved from an interstitial position on the ancestral primate chromosome to a very subtelomeric position in chimpanzee and humans by a pericentric inversion(s). Pathological 9p rearrangements may be the consequence of an evolutionary chromosome breakpoint in close proximity to the sex-reversal region. European Journal of Human Genetics (2000) 8, 167-173.
\end{abstract}

Keywords: chromosome evolution; comparative mapping; DM RT1; FISH; monosomy 9p; XY sex reversal; YAC

\begin{abstract}
Introduction
$X Y$ sex reversal occurs with a frequency of up to 1 in 20000 births. $^{1}$ Most cases are sporadic. At birth, infants with $X Y$ sex reversal appear to be female. At puberty, the girls show primary amenorrhea and do not develop the secondary sex characteristics of a normal female phenotype. However, despite the presence of only a single $X$ chromosome they do not exhibit the typical stigmata of Turner syndrome. Although most patients have female internal sex organs, they may present with bilateral streak gonads or testicular tissue on one side and a streak gonad on the other. Due to the presence of a $\mathrm{Y}$ chromosome, there is a remarkably high risk of up to $30 \%$ for developing malignant gonadoblastoma. Therefore, early gonadectomy is strongly recommended. ${ }^{2}$

The molecular characterisation of $X Y$ females has al ready led to the identification of several sex-determining genes in addition to the male dominator factor on the Y chromosome,
\end{abstract}

Correspondence: Thomas Haaf, Max Planck Institute of Molecular Genetics, Ihnestrasse 73, 14195 Berlin, Germany. Tel: +49308413 1251; Fax: +49308413 1383; E-mail: haaf@molgen.mpg.de Received 28 July 1999; revised 15 September 1999; accepted 23 September 1999
$\mathrm{SRY}{ }^{3} \mathrm{DAX} 1$ in the dosage sensitive sex-reversal locus on the $X^{4}{ }^{4}$ the steroidogenic factor 1 (SF1) on $9 q,{ }^{5}$ the SRY-related box gene9 (SOX9) on $17 q,{ }^{6,7}$ and the Wilms' tumor gene (W T1) on 11p. ${ }^{8}$ However, mutations in these genes, which are required for normal gonadal development, have only been found in a relatively small number of sex-reversal cases, ie $15 \%$ of $X Y$ females show mutations in SRY. ${ }^{9,10}$ This strongly suggests the involvement of additional sex-determining genes. Deletion of the distal short arm of chromosome9p21-24 is associated with failure of the testicular development and XY feminisation. ${ }^{11-13}$ The critical region for $X Y$ sex reversal has been narrowed down to band 9p24.3 and contains two candidate genes, DMRT 1 (doublesex and mab-3 related transcription factor 1 , formerly named DMT1) and DMRT2, which are expressed in the adult testis. Both DMRT 1 and DMRT 2 contain a DNA-binding DM domain and share significant structural homology with male sexual regulatory genes from Caenorhabditis elegans (mab-3) and Drosophila melanogaster (dsx). ${ }^{14,15}$

Here we have used FISH with YACs from human chromosome9p to determine the size of two $9 p$ deletions associated with $X Y$ sex reversal. Comparative mapping of human $9 p$ 
YACs on chromosomes of Old and New World monkeys, and of great apes, indicates that the critical region for $X Y$ sex reversal repeatedly changed its chromosomal position during primate evolution.

\section{Materials and methods \\ Case histories}

Case1: 46, XY, der(9), t(8;9)(q23.1;p23) The patient inherited the derivative chromosome 9 from her mother who carries a reciprocal $t(8 ; 9)$ translocation. The clinical features of patient 1, who is monosomic for 9p23-pter and trisomic for 8q23-qter, have been described in detail elsewhere. ${ }^{16}$ Briefly, the infant presented with ambiguous genitalia (scrotal hypospadias and blind ending sinus urogenitalis with no evidence of Mullerian structures), craniofacial dysmorphies (flat facies with depressed nose, premature closure of the frontal suture, short upper lip and a deep groove and everted lower lip, low set small ears), and unilateral hydronephrosis. Histology of the gonads showed testicular morphology with few spermatocytes and rare gonocytes. Endocrinological parameters were normal. No mutations were found in the SRY, androgen receptor, and alpha-reductase genes.
Case2: 46, XY, der(9), t(9;13)(p22;q14) Patient 2, who is newly reported here, carries partial monosomy 9p22-pter and partial trisomy 13q14-qter and shares clinical features with both the del(9p) syndrome (ie multiple craniofacial abnormalities) ${ }^{17}$ and trisomy 13 (ie polydactyly, low set deformed ears). ${ }^{18}$ The mother is a balanced $t(9 ; 13)$ translocation carrier. The patient is the product of an uneventful pregnancy to healthy non-consanguineous parents. The birth weight was $3150 \mathrm{~g}$, and length was $51 \mathrm{~cm}$. The external genitalia were female and ectopic gonads were not pal pable. She showed hypotonia and multiple dysmorphic features, such as postaxial hexadactyly of hands and feet, scaphocephaly, macrocornea, prominent nose, high-arched palate and micrognathia, low set and dysplastic auricles of the ear, and small tubular thorax with wide intermammilary distance. Since the neonatal period she showed delayed psychomotor development and suffered from epileptic (grand mal and petit mal) seizures.

\section{DNA probes}

YAC clones were selected from the CEPH mega-YAC library and obtained through the Resource Center of the German

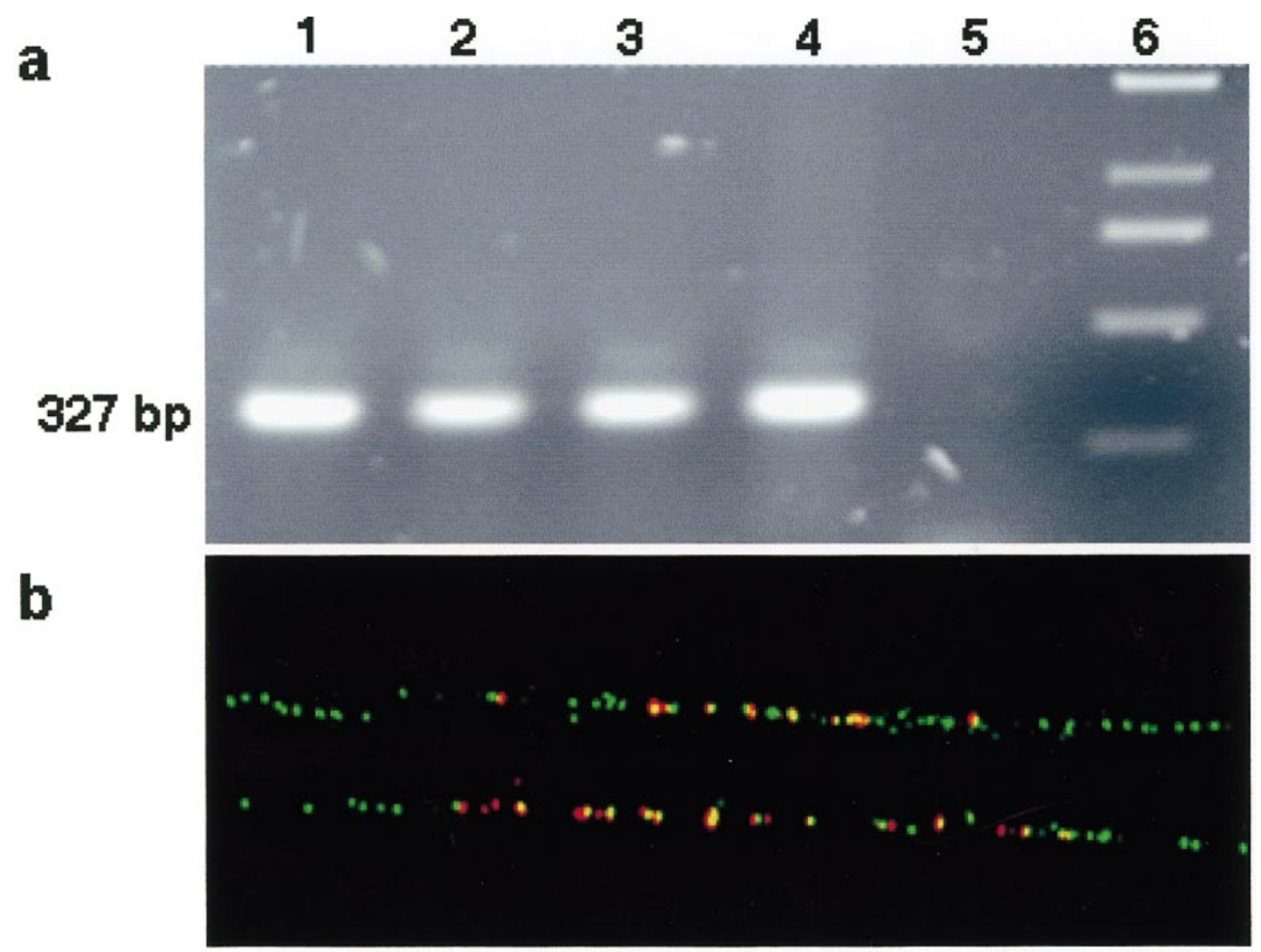

Figure 1 Identification of a YAC from the 9p sex-reversal region a PCR amplification of a 327-bp DMRT1 fragment from PAC 8 (Lane1), YAC 765H2 (Lane2), total genomic DNA (Lane3), and complementary DM RT1 DNA (AA412330) (Lane4). Lane5 contains a negative control, lane 6 size markers b hybridisation of FITC-labelled YAC 765H2 (green) and Cy3-labelled PAC 8 (red) to extended chromatin fibres. The entire PAC is contained in the linear YAC signal. 
Human Genome Project. Details on genetic markers of individual YACs were obtained through public databases. The human YAC inserts were isolated by pulsed field gel electrophoresis and amplified by degenerate oligonucleotideprimed (DOP) polymerase chain reaction (PCR). ${ }^{19}$ PAC 8 contains the DMRT1 gene. DOP-PCR products of microdissected chromosomes 9 were used for chromosome painting. DNA probes were labelled with either biotin-16-dUTP or digoxigenin-11-dUTP (Boehringer Mannheim) by standard nick translation.

\section{Fluorescence in situ hybridization (FISH)}

Metaphase chromosomes were prepared from EBV-transformed lymphoblastoid cell lines (in case1, great apes, and Old World monkeys) and fibroblasts (in case 2 and $\mathrm{New}$ World monkey). Extended chromatin fibres for high-resolution mapping were prepared from agarose-embedded cells according to the method described by Heiskanen et al. ${ }^{20}$ Standard FISH protocols were followed. ${ }^{21}$ Oncor imaging software was used to capture grey scale CCD images and to superimpose these on a colour image. Oncor imaging software was also used to convert the DAPI image into a G-banded metaphase for identification of the chromosomes.

\section{PCR analysis}

PCR amplification was done in a final volume of $50 \mu \mathrm{l}$ containing $100 \mathrm{ng}$ of YAC, PAC, CDNA, or total genomic DNA and $12.5 \mathrm{pmol}$ each of the primers DMRT1-A, 5'-gacgagtgagcagtgcctgc-3' and DMRT1-B, 5'-catttagaggcacacaaatggc-3'. After an initial denaturation at $94^{\circ} \mathrm{C}$ for $2 \mathrm{~min}, 30$ cycles were carried out with denaturation at $94^{\circ} \mathrm{C}$ for $30 \mathrm{~s}$, annealing at $60^{\circ} \mathrm{C}$ for $40 \mathrm{~s}$, and extension at $72^{\circ} \mathrm{C}$ for $50 \mathrm{~s}$. A final incubation at $72^{\circ} \mathrm{C}$ for $3 \mathrm{~min}$ was performed at the end of the reaction.

\section{Results}

Because it is difficult to analyse subtle rearrangements involving the subtelomeric chromosome regions by classical banding analysis, in many cases FISH will be the best method to detect monosomy for the $9 p$ sex-reversal region. To this end, we have identified a CEPH-YAC, 765H2 (D9S1858, 0 cM) containing DMRT 1 which is, so far, the best candidate testisdetermining gene in the critical region 9p24.3. ${ }^{14,15}$ PAC 8 also contains the DMRT1 gene (C. Ottolenghi, 1999, un published results). By PCR we have amplified a 327-bp fragment from the 3'-end of DMRT1 from both YAC $765 \mathrm{H} 2$ and PAC 8 (Figurela). Fibre FISH showed that YAC $765 \mathrm{H} 2$ contains the complete PAC 8 sequence (Figure1b). Due its large 1510-kb insert, the non-chimeric YAC $765 \mathrm{H} 2$ generates high-intensity and region-specific FISH signals on both metaphase and interphase nuclei, which are clearly visible by eye through the microscope. As a tool for the molecular cytogenetic analysis of cytogenetically cryptic and visible chromosome
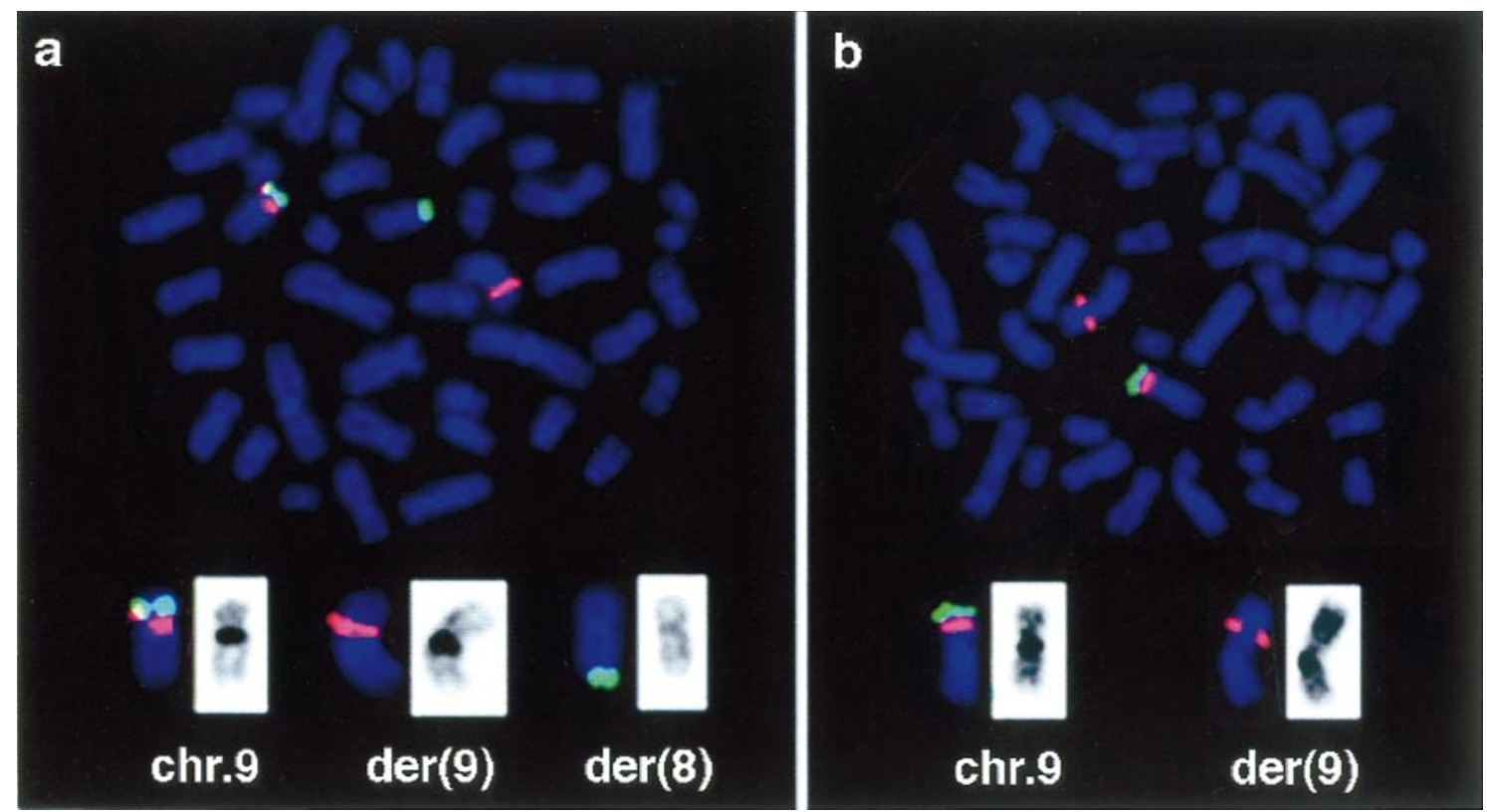

Figure 2 FISH mapping of 9p YACs in sex-reversal patients a hybridisation of YAC 765H2 (0 cM) and YAC 784B4 (20 cM) to chromosomes of patient 1's mother carrying a t( $8 ; 9)$ translocation. The DM RT1-containing YAC 765H2 (green) is located on the normal chromosome 9 and the der(8). YAC 784B4 (red) lies on both the normal and the der(9). This implies monosomy for YAC 765H2 in patient 1 who inherited only the der(9) b hybridisation of YAC 765H2 and 762D7 (27 CM) on chromosomes of patient 2. YAC 765H2 hybridisation signals (green) are seen on the normal chromosome 9 but not on the der(9). YAC 767D7 (red) is present on both the normal and the der(9). White inserts show the converted DAPI (G-like) bands of the hybridised chromosomes. 
rearrangements, we have developed a large set of cytogenetically and genetically anchored YAC probes, approximately one every $3-5 \mathrm{cM}$, that are more or less evenly spaced throughout the entire human chromosome complement. ${ }^{21}$ Here we have used this probe set to determine the size of $9 p$ deletions in two patients with $X Y$ sex reversal.

The first patient inherited the der(9) of a balanced $t(8 ; 9)$ translocation, resulting in monosomy for 9p23-pter. ${ }^{16}$ FISH mapping of STS-containing YAC clones from band 9p21-24 on chromosomes of the patient's mother demonstrated a $9 p$ deletion ranging from D9S1858 (YAC 765H2, $0 \mathrm{cM}$ ) to D9S286 (YAC 853F4, 17 cM) (Figures2a and 3). Our results are consistent with previous microsatellite analysis indicating hemizygosity for markers D9S288 and D9S129. ${ }^{16}$ The second patient inherited the $\operatorname{der}(9)$ of a $t(9 ; 13)$ and was monosomic for 9p22-pter. By FISH this patient exhibited a deletion ranging from D9S1858 (YAC 765H2, 0 CM) to D9S256 (YAC 961E4, 23cM) (Figures2b and 3). Both YACs $853 F 4$ (17 cM) and 961E4 (23cM) had been mapped previously to chromosome band 9p23. However, FISH mapping on normal chromosomes may be one band in error. When characterising a larger number $(>50)$ of translocations we noticed that breakpoint localisation by banding analysis can err by several bands. Therefore, the size of deletions that have been FISH mapped with genetically anchored YACs is expressed most accurately in centimorgans. The DMRT1containing PAC 8 was also missing on the der(9) chromosomes of both patients (data not shown).

The subtelomeres are proving to be a highly dynamic region of the human genome that play an important role in human chromosome pathology ${ }^{22,23}$ and during chromosome evolution. ${ }^{24}$ In order to study the chromosomal phylogeny of the sex-reversal region on human 9p, the 14YACs listed in Figure 3 as well as PAC 8 were hybridised on chromosomes of chimpanzee (Pan troglodytes, PTR), gorilla (Gorilla gorilla, GGO), orangutan (Pongo pygmaeus, PPY), gibbon (Hylobates syndactylus, HSY), silvered leaf monkey (Presbytis cristata, P.cr.), and marmoset (Callithrix geoffrei, CGE). In humans (Figure2), chimpanzee (Figure4a), and gibbon (Figure4d), the DMRT1-containing YAC $765 \mathrm{H} 2$ lay very close to the tel omere. The human chromosome 9 differs from the homologous PTR IX by a small pericentric inversion in the chimpanzee and a large block of constitutive heterochromatin in the human long arm. $^{25}$ In the highly rearranged

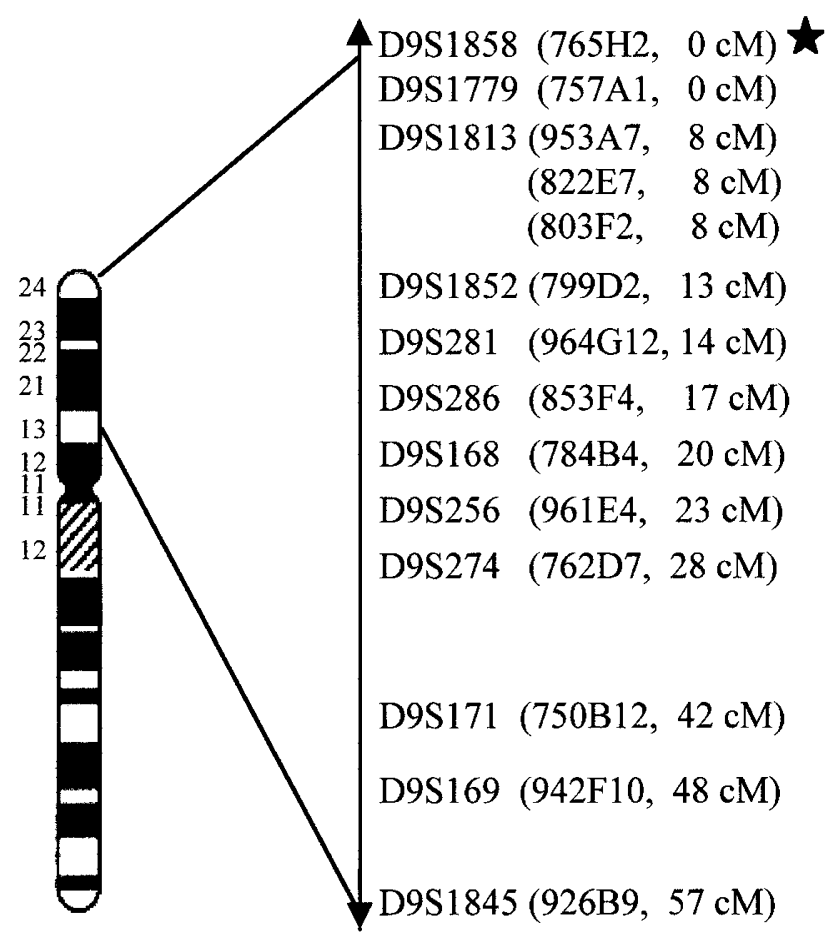

Chr. 9

STS YAC

$\mathrm{cM}$

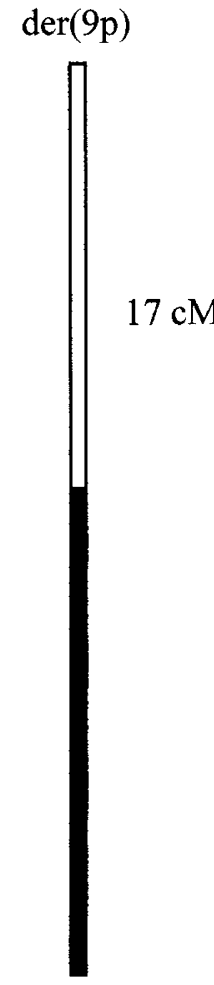

46, XX,t(8;9) (q23.1;p23)

46, $\mathrm{XY}, \mathrm{t}(9 ; 13)(\mathrm{p} 22 ; \mathrm{q} 14)$

Figure 3 Schematic diagram summarising the FISH mapping results of $9 p$ YACs on the derivative chromosomes 9 . The D numbers of the Généthon polymorphic STS markers that place the hybridised YACs on the genetic map of the chromosome are listed with their distance in centimorgans from the short-arm telomere. YACs spanning $0-17 \mathrm{cM}$ on $9 p$ are deleted in patient 1 and $0-23 \mathrm{cM}$ in case 2 . Star indicates the DMRT1-containing YAC. 


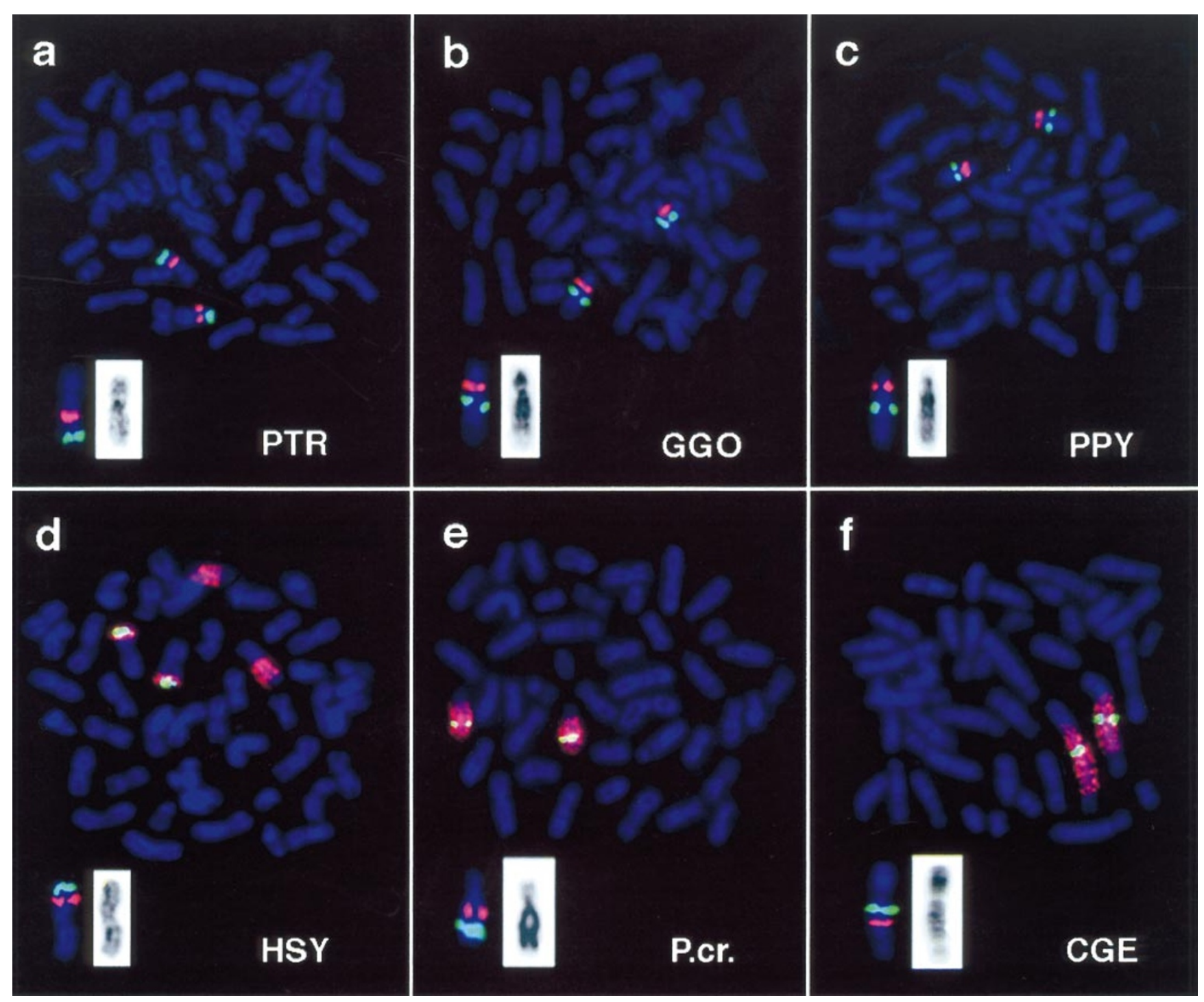

Figure 4 Chromosomal rearrangements involving the 9p sex-reversal region during primate evolution. YAC $765 \mathrm{H} 2(0 \mathrm{cM}$, green) and YAC 926B9 (57 cM, red) were hybridised on chromosomes of a chimpanzee, b gorilla, c orangutan, d gibbon, e silvered leaf monkey, and f marmoset. White inserts show the converted DAPI (G-like) bands of the hybridised chromosomes. To visualise the HSA 9 homologs in HSY, P.cr., and CGE, metaphases were co-hybridised with the DM RT1-containing YAC $765 \mathrm{H} 2$ (green) and a chromosome specific DNA library (red).

gibbon karyotype, ${ }^{26}$ sequences homologous to HSA 9 are diverged on two chromosome pairs (Figure4d). We have mapped an evolutionary breakpoint between YAC 926B9 (57 cM) and 887A2 (D9S166, 65cM) (data not shown). The GGO, PPY, and P.cr. homologs of human chromosome 9 are acrocentric. The human 9p YAC contig mapped to an interstitial site in either the proximal (GGO and PPY) or middle (P.cr.) part of the long arm of the homologous primate chromosome, with YAC $765 \mathrm{H} 2(0 \mathrm{cM}$ in humans) being the most distal and YAC $926 \mathrm{~B} 9(57 \mathrm{cM})$ the most proximal (Figure $4 b, c$, and e). In the New World monkey CGE, the homolog of HSA 9 is part of a larger submetacentric chromo- some. Similar to GGO and PPY, the human 9p YACs lay interstitially within the chromosome 9 part (Figure4f).

Taken together, our results suggest that this interstitial localisation represents the ancestral chromosome type. The subtelomeric location of the sex-reversal region on human $9 p$ has arisen through a large pericentric inversion in a progenitor of chimpanzee and humans, followed by another (small) pericentric inversion in the chimpanzee lineage and acquisition of paracentromeric heterochromatin in the human lineage. This implies the existence of an evolutionary breakpoint in the subtelomeric region between YAC $765 \mathrm{H} 2$ (DS91858, 0cM) and the human 9p telomere. Interestingly, 
an independent chromosomal mutation (reciprocal translocation) in the gibbon has also moved DMRT1 close to the chromosome end.

\section{Discussion}

Deletions of the distal short arm of chromosome9p21-24 have been reported in more than 10 cases to be associated with $X Y$ sex reversal ${ }^{11-16}$ There is no correlation between the extent of sex reversal and the size of the del(9p). However, larger deletions leading to hemizygosity of many contiguous genes are associated with mental retardation and craniofacial abnormalities, in addition to partial or complete gonadal dysgenesis and ambiguous external and internal genitalia. The smallest reported sex-reversing del(9p) define a critical region from markers D9S1858/D9S1779 to the 9p telomere, which may span only several hundred kilobases. ${ }^{27}$ Here we have FISH mapped the 9p deletions in two XY females in fine detail. Since the deleted DNA segments are much larger ( $17 \mathrm{cM}$ and $23 \mathrm{cM}$, respectively) than the critical sex-reversal region, it is not unexpected that both sex-reversed patients also show craniofacial and other dysmorphic features. DMRT 1 and DMRT2, so far the only candidate testisdetermining genes in the sex-reversal region, are located very distally on chromosome9p and hemizygous in all XY females with 9p deletions. ${ }^{15}$ FISH with YAC $765 \mathrm{H} 2$ allows rapid diagnosis of monosomy for the sex-reversing $9 p$ region. In contrast to microsatellite typing, it does not depend on the availability of material from the patient's parents.

The exact mechanism underlying sex reversal in $X Y$ females with monosomy $9 p$ remains unclear. Because of their chromosomal localisation and the fact that their male regulatory function is highly conserved across evolution, DMRT 1 and DMRT 2 have been implicated in testis development. It has been proposed that hemizygosity for both genes may be required to cause $X Y$ sex reversal. ${ }^{15}$ Since the two proteins are highly similar in their DM domains, they may perform similar functions and be at least partially interchangeable. Since mutations in DMRT1 and DMRT2 seem to be very infrequent in $\mathrm{XY}$ sex reversal, examination of animal models may be the best way to analyse the role of DMRT genes in sex determination. To this end, we have recently isolated an ortholog of human DMRT 1 on the chicken Z sex chromosome. ${ }^{28}$ Similar to the $9 p$ sex-reversal in humans, it may be that the two Z-linked copies of DMRT 1 are required for avian testis formation, whereas a single copy on the $Z$ along with the $W$ sex chromosome leads to female sex differentiation.

Comparative YAC mapping demonstrated that the sexreversing region was involved in independent chromosomal rearrangements during primate evolution. Both a pericentric inversion in a common ancestor of humans and chimpanzee (after divergence of the gorilla lineage) and a reciprocal translocation in the gibbon moved the DMRT1 and DMRT2 genes very close to the chromosome end. This implies the presence of an evolutionary breakpoint(s) in the small DNA segment between (or within) the sex-reversal region and the human $9 p$ telomere. ${ }^{27}$ We speculate that this evolutionary breakpoint region may account for the relatively frequent involvement of the sex-reversal region in $9 p$ deletions.

\section{Acknowledgements}

We thank Gerd Scherer for fibroblast cultures and Lisa Riesselmann, Susanne Freier, and Dietmar Vogt for excellent technical assistance. This work was supported by grant Ha1374/5-1 from the Deutsche Forschungsgemeinschaft. Z Shan was supported by the Yunnan Province Science \& Technology Commission.

\section{References}

1 Robinson A, Linden MG: Ambiguous genitalia and hermaphroditism. In: Robinson A (ed): Clinical Genetics Handbook, 2nd edn. Blackwell Scientific: Boston, 1993, pp 309-315.

2 Sultana R, Myerson D, Disteche CM: In situ hybridization analysis of the $\mathrm{Y}$ chromosome in gonadoblastoma. Genes Chromosomes Cancer 1995; 13: 257-262.

3 Sinclair AH, Berta P, Palma MS et al: A gene from the human sexdetermining region encodes a protein with homology to a conserved DNA-binding motif. Nature 1990; 346: 240-244.

4 Bardoni B, Zanaria E, Guioli S et al: A dosage-sensitive locus at chromosome Xp21 is involved in male to female sex reversal. Nat Genet 1994; 7: 497-501.

5 Luo X, Ikeda Y, Parker KL: A cell-specific nuclear receptor is essential for adrenal and gonadal development and sexual differentiation. Cell 1994; 77: 481-490.

6 Foster JW, Dominguez-Steglich MA, Guioli $\mathrm{S}$ et al: Campomelic dysplasia and autosomal sex reversal caused by mutations in an SRY-related gene. Nature 1994; 372: 525-530.

7 Wagner T, Wirth J, Meyer J et al: Autosomal sex reversal and campomelic dysplasia are caused by mutations in and around the SRY-related gene SOX9. Cell 1994; 79: 1111-1120.

8 Call KM, Glaser T, Ito CY et al: Isolation and characterization of a zinc finger polypeptide gene at the human chromosomell Wilms' tumor locus. Cell 1990; 60: 509-520.

9 Hawkins JR: Genetics of XY sex reversal. J Endocrinol 1995; 147: 183-187.

10 Schafer AJ, Goodfellow PN: Sex determination in humans. Bioessays 1996; 18: 955-963.

11 Flejter WL, Fergestad J, Gorski J, Varvill T, Chandrasekharappa S: A gene involved in $X Y$ sex reversal is located on chromosome9, distal to marker D9S1779. Am J Hum Genet 1998; 63: 794-802.

12 Guioli S, Schmitt K, Critcher R et al: Molecular analysis of $9 p$ deletions associated with $X Y$ sex reversal: refining the localization of a sex-determining gene to the tip of the chromosome. Am J Hum Genet 1998; 63: 905-908.

13 Veitia RA, Nunes M, Quintana-Murci L et al: Swyer syndrome and $46, X Y$ partial gonadal dysgenesis associated with 9p deletions in the absence of monosomy-9p syndrome. Am J Hum Genet 1998; 63: 901-905.

14 Raymond CS, Shamu CE, Shen MM et al: Evidence for evolutionary conservation of sex-determining genes. Nature 1998; 391: 691-695.

15 Raymond CS, Parker ED, Kettlewell JR et al: A region of human chromosome $9 p$ required for testis development contains two genes related to known sexual regulators. Hum Mol Genet 1999; 8: 989-996.

16 Pfeiffer RA, Rauch A, Trautmann $U$ et al: Defective sexual development in an infant with 46, XY, $\operatorname{der}(9) t(8 ; 9)(q 23.1$; p23)mat. Eur J Pediatr 1999; 158: 213-216.

17 Huret JL, Leonard C, Forestier B, Rethore MO, Lejeune J: Eleven cases of del(9p) and features from 80 cases. J Med Genet 1988; 25 741-749. 
18 Noel B, Quack B, Rethore MO: Partial deletions and trisomies of chromosome13; mapping of bands associated with particular malformations. Clin Genet 1976; 9: 593-602.

19 Telenius H, Carter NP, Bebb CE, Nordenskjold M, Ponder BA, Tunnacliff A: Degenerate oligonucleotide-primer PCR: general amplification of target DNA by a single degenerate primer. Genomics 1992; 13: 718-725.

20 Heiskanen M, Kallioniemi O, Palotie A: Fiber-FISH: experiences and a refined protocol. Genet Anal Biomol Eng 1996; 12: 179-184.

21 Wirth J, Nothwang H-G, van der Maarel S et al: Systematic characterization of disease associated balanced chromosome rearrangements by FISH: cytogenetically and genetically anchored YACs identify microdeletions and candidate regions for mental retardation genes. J Med Genet 1999; 36: 271-278.

22 Ledbetter DH: Cryptic translocations and telomere integrity. Am J Hum Genet 1992; 51: 451-456.

23 Flint J, Wilkie A, Buckle V, Winter R, Holland A, McDermid H: The detection of subtelomeric chromosomal rearrangements in idiopathic mental retardation. Nat Genet 1995; 9: 132-139.
24 Kingsley K, Wirth J, van der Maarel S, Freier S, Ropers HH, Haaf T: Complex FISH probes for the subtelomeric regions of all human chromosomes: comparative hybridization of CEPH YACs to chromosomes of the Old World monkey Presbytis cristata and great apes. Cytogenet Cell Genet 1997; 78: 12-19.

25 Yunis JJ, Prakash O: The origin of man: a chromosomal pictorial legacy. Science 1982; 215: 1525-1530.

26 Jauch A, Wienberg J, Stanyon $\mathrm{R}$ et al: Reconstruction of genomic rearrangements in great apes and gibbons by chromosome painting. Proc Natl Acad Sci USA 1992; 89: 8611-8615.

27 Report on the Sixth International Workshop on Chromosome9: Denver, Colorado, USA. 27.10.1998. World Wide Web URL: http://www.gene.ucl.ac.uk/chr9/report98.htm.

28 Nanda I, Shan Z, Schartl M et al: 300 million years of conserved synteny between chicken $Z$ and human chromosome9. Nat Genet 1999; 21: 258-259. 